\title{
A proteção do patrimônio cultural brasileiro e sua relação com a teoria de Viollet-le-Duc
}

\author{
William Vicari Filho*
}

\begin{abstract}
Resumo Se entendermos as tradições como construções históricas recentes, visando a criação de uma identidade nacional, é possível problematizar as narrativas sobre os passados nacionais. Este artigo pretende questionar a atuação do IPHAN nesse sentido, tratando sua abordagem nas restaurações do patrimônio brasileiro. Para isso, o pensamento de Viollet-Le-Duc, para quem "restaurar um edifício é restituí-lo a um estado completo que pode nunca ter existido num momento dado", foi comparado aos pensamentos de Mário de Andrade e Lúcio Costa, dois nomes importantes no processo de criação da narrativa identitária do Brasil. A conclusão atingida é que essas linhas de pensamento convergem, com as propostas do arquiteto francês sendo usadas em diversos momentos pelo órgão responsável pela preservação da história nacional.
\end{abstract}

Palavras-chave: restauração, barroco, colonial.

\section{La protección del patrimonio cultural brasileño y su relación con la teoría de Viollet-le-Duc}

\begin{abstract}
Resumen Las tradiciones son construcciones históricas con el objetivo de crear una identidad nacional, siendo posible cuestionarlos. El siguiente artículo pretende cuestionar el papel de IPHAN en la restauración del patrimonio brasileño. Para esto, el pensamiento de Viollet-Le-Duc, para quien "Restaurar un edificio es restaurarlo a un estado completo que nunca pudo haber existido en un momento dado", se comparó con los pensamientos de Mário de Andrade y Lúcio Costa, dos nombres importantes en el proceso de desarrollo de la narrativa de identidad de Brasil. La conclusión a la que se llegó es que estas líneas de pensamiento convergen, con las propuestas del arquitecto francés utilizadas en varias ocasiones por el organismo responsable de preservar la historia nacional.
\end{abstract}

Palabras clave: restauración, barroco, colonial.

\section{The protection of Brazilian cultural heritage and the relation with Viollet-le-Duc's theory}

\begin{abstract}
If we understand traditions as recent historical constructions, aiming at the creation of a national identity, it is possible to problematize the narratives about the national past. This article's objective is to question the acting of IPHAN in the restoration of Brazilian cultural heritage. For this, Viollet-Le-Duc's theory, for whom "restoring a building is restoring it to a complete state that may never have existed at a given moment", was compared to the actions and thoughts of Mário de Andrade and Lúcio Costa, two important names in the Brazilian's identity development. The conclusion reached is that these lines of thought converge, with the French architect's proposals being used more than once by the group responsible for the national history's preservation.
\end{abstract}

Keywords: restoration, baroque, colonial. 
Em seu livro "A Invenção das Tradições", Eric Hobsbawn aponta que costumes tidos como antigos podem ser, na realidade, recentes. Essa cultura inventada é um conjunto de práticas que visam gravar certos hábitos e valores na sociedade através de uma continuidade artificial com o passado histórico, tendo como objetivo a legitimação de instituições e de certa coesão social imposta pela repetição. Essas tradições transformamse de acordo com as mudanças da sociedade, adaptando velhos modelos e elementos ao novo cenário, e muitas vezes se manifestando fisicamente através dos monumentos. ${ }^{1}$

Os monumentos, por sua vez, podem ser entendidos como um aglomerado de diferentes tempos históricos em um único espaço físico, criando o que Milton Santos definiu como "rugosidade na paisagem". Já como patrimônio histórico, fazem parte do grupo de bens culturais de uma comunidade, constituído por diversos objetos ligados por seu passado comum. Tais bens possuem uma importância significativa para o discurso oficial das Nações, levando à criação de diversos mecanismos para sua proteção e perpetuação, dentre os quais destaca-se a restauração.

Antes de se debruçar sobre a questão do restauro dos patrimônios no Brasil, é importante notar que, como posto por Marilena Chaú, a formação identitária brasileira se deu através do Mito Fundador de uma nação de grandeza natural com um povo pacífico e sem preconceitos, cuja História sequer presenciou derramamentos de sangue. Com suas raízes remetendo ao Século XVI, tal narrativa tornou-se a solução imaginária para os conflitos impossíveis de serem resolvidos na realidade, como lutas populares, resistência de grupos tradicionais, e mesmo o surgimento da Classe Média. Fundador por se ligar a um passado incessante, esse mito bloqueia a percepção da realidade e sempre encontra novas formas de se exprimir, criando uma espécie de religião cívica sob a imagem do patriotismo. ${ }^{1}$

E foi justamente aproveitando a esteira do patriotismo do Governo Vargas e a busca pelo desenvolvimento de uma Identidade Nacional que os Modernistas da Semana de 22 acenderam o debate sobre o valor da Arte Colonial, materializando a necessidade de uma instituição para a proteção de monumentos. Em 1937, Getúlio Vargas aprovou uma série de leis que versavam sobre o patrimônio histórico e artístico, levando à criação do Serviço do Patrimônio Histórico e Artístico Nacional (SPHAN), atualmente conhecido como Instituto Histórico e Artístico Nacional (IPHAN). Na fase denominada como "Heróica", compreendida entre sua fundação e o ano de 1968, o órgão buscou a criação de uma Cultura e Identidade Nacional, apoiando-se nas restaurações estilísticas que são vistas por Claudio Galli como "sem preparação suficiente sobre a Arquitetura brasileira e suas técnicas construtivas. ${ }^{3}$

* William Vicari Filho é Historiador, Mestrando do Programa de Pós-Graduação em História da Arte da UNIFESP, ORCID $<$ https://orcid.org/0000-00027401-9818>.
Para entender a ligação entre os Modernistas e a Arte Colonial, precisamos retroceder ao ano de 1919, quando Mario de Andrade foi à cidade de Ouro Preto pela primeira vez, buscando um gênio artístico verdadeiramente brasileiro nas construções civis e religiosas das Minas Gerais. Com as experiências adquiridas em tal viagem o autor 
1 HOBSBAWM, Eric. A invenção das tradições. Rio de Janeiro; Paz e Terra, 2006, p. 9-23.

2CHAUI, Marilena. "Brasil: mito fundador e sociedade autoritária". In: ROCHA, André (org.). Marilena Chauí. Manifestações ideológicas do autoritarismo brasileiro. Belo Horizonte/ São Paulo; Autêntica/ Fundação Perseu Abramo, 2013, vol. 2, p. 147-237

3 GALLI, Claudio, et al. A teoria e prática do restauro arquitetônico: A influência da cultura européia e seus desdobramentos na realidade brasileira. São Paulo: Revista Arq.urb, n. 16, Universidade São Judas Tadeu 2016, p.8.

4 NATAL, Caion Meneguello. Ouro Preto: A construção de uma cidade histórica, 1891-1933. Dissertação de Mestrado. Campinas: UNICAMP, 2007, p. 109.

5IDEM, p. 112

6 ANDRADE, Mário. Apud, NATAL, Caion Meneguello. Ouro Preto: A construção de uma cidade histórica, 1891-1933. Dissertação de Mestrado. Campinas: UNICAMP, 2007, p. 113.

7 NATAL, Caion Meneguello, Op Cit., p. 114. escreveu "A Arte Religiosa no Brasil", elegendo os conjuntos arquitetônicos baianos, cariocas e mineiros como os legítimos representantes da cultura nacional, pioneiros no desenvolvimento da identidade do país. Para ele, a partir do século XVIII artistas como Aleijadinho e Mestre Valentim desenvolveram uma Arte insubmissa à Metrópole, primando pela originalidade e inovação.

Tendo como ponto de partida o Barroco lusitano, esses artistas precisavam adicionar suas próprias soluções aos problemas que iam surgindo durante a execução das obras, adaptando princípios europeus aos meios e recursos americanos. Pelo grau da religiosidade brasileira, foi na execução dos templos que a arquitetura encontrou o terreno fértil para se tornar a primeira e maior expressão da identidade nacional, na lógica de Andrade. E, apesar de estudar a Bahia e Rio de Janeiro, a região de Minas Gerais foi a apontada pelo autor como epitome dessa incipiente cultura. ${ }^{4}$

Os motivos que levaram Mário de Andrade a considerar as Minas como o território propicio ao desenvolvimento artístico foram questionados pelo historiador Caion Menguello Natal, em sua dissertação de Mestrado. Para ele, antes da segunda metade do Século XVIII era impossível encontrar as condições necessárias para se criar uma Arte capaz de ilustrar o que era o Brasil, pois o mesmo carecia de coesão territorial e não havia passado por eventos que sedimentassem uma visão unificada de sua História ${ }^{5}$. Porém, já na segunda metade do referido século a situação teria começado a mudar, com Mário de Andrade dizendo que

A Colônia dera por dois séculos certas expressões grandiosas da sua significação histórica e social. A Guerra Holandesa, o Bandeirismo, Gregório de Matos, a igreja e convento de S. Francisco, na Bahia. Todos estes fenômenos, porém, são esporádicos, seccionados geográfica, cronológica e socialmente. Embora expressões muito específicas de colonialismo, são frutos das condições de determinadas capitanias, não são frutos da Colônia. Não resultam da coletividade colonial. Expressões desta principiam aparecendo com freqüência só mesmo da segunda metade do século dezoito em diante, como a posição burocrática e centralizadora da cidade do Rio de Janeiro, com a expansividade antimarítima das Minas Gerais, com a influência do homem colonial sobre a Metrópole, como a normalização do mestiço. ${ }^{6}$

Andrade era defensor da ideia de que o isolamento geográfico das Minas em relação ao litoral favoreceu o desenvolvimento de uma Arte genuína. Caion Natal desenvolve tal apontamento, colocando que o desgaste da economia mineradora, somado ao já citado isolamento, contribuiu para tornar a região em uma "estância mais livre, porque isolada e empobrecida, das influências portuguesas". Em linhas gerais, podemos aferir que, em um momento de declínio financeiro, os artífices locais foram forçados a buscar saídas menos suntuosas para as obras, e com isso acabaram gerando um estilo arquitetônico "original". .

Para deixar as ideias de Mario de Andrade sobre tal tema mais claras, podemos recorrer a uma citação sua, presente na já mencionada dissertação de Caion Natal, onde o Modernista diz que:

Foi nesse meio oscilante de inconstâncias [Minas Gerais] que se desenvolveu a mais característica arte religiosa do Brasil. A Igreja pôde aí, mais liberta das influências de 
8 ANDRADE, Mário. Apud, NATAL, Caion Meneguello. Op. Cit., p. 115.

9 ANDRADE, Mário. Apud, NATAL, Caion Meneguello. Ouro Preto: A construção de uma cidade histórica, 1891-1933. Dissertação de Mestrado. Campinas: UNICAMP, 2007, p. 119.
Portugal, proteger um estilo mais uniforme, mais original, que os que abrolhavam podados, áulicos, sem opinião própria nos dois outros centros [Rio e Bahia]. Estes viviam de observar o jardim luso que a miragem do Atlântico Ihes apresentava continuadamente aos olhos: em Minas, se me permitirdes o arrojo da expressão, o estilo barroco estilizou-se. As igrejas construídas quer por portugueses mais aclimados ou por autóctones algumas, provavelmente, como o Aleijadinho, desconhecendo até o Rio e a Bahia, tomaram um caráter mais bem determinado e, poderíamos dizer, muito mais nacional. ${ }^{8}$

Apesar das críticas aos excessos do Barroco lusitano, o objetivo de Mário de Andrade não era provocar uma ruptura entre o Estilo brasileiro e sua matriz portuguesa, mas sim valorizar a criação nacional, estabelecendo "também um código próprio a este produto, uma significação histórica irredutível". É justamente através da elevação dessa tradição que o Modernista tentaria inseri-la em uma dinâmica universal da Arte, onde sua função seria a de estabelecer a base das manifestações de uma nacionalidade. Para ele, a ligação entre a Arte Barroca das Minas e o estereótipo nacional chegava ao ponto de permitir o traçar de paralelos entre a arquitetura de Aleijadinho e o "Ser Brasileiro".

Inclusive, as primeiras propostas para a construção de uma identidade nacional feitas por Mário de Andrade surgiram a partir do estudo das obras do Artista Mineiro, que se tornou um objeto central para entender a concepção que os Modernistas tinham de Nacionalismo. Para eles, se a segunda metade do Século XVIII viu o florescer de uma arte genuinamente nacional, ela foi morta pelo Academicismo do Século seguinte e continuou ausente até o período de Andrade e seus companheiros. Portanto, o grupo defendia a necessidade de recuperar essa "esquecida" tradição artística. ${ }^{9}$

Essa ligação entre o Barroco e o "Ser Brasileiro" pode ser explicada através do que Eduardo Bezerra de Menezes entendeu como a "cosmovisão matricial do ethos cultural brasileiro", a visão de mundo que coloca o Barroco como a matriz dos hábitos culturais nacionais. Para ele, com a ressignificação que o Modernismo deu a essa Escola Artística, que passou a ser caracterizada como um fenômeno trans-histórico e sem fronteiras geográficas ou temporais bem-definidas, é possível entender o Barroco como a Arte Fundadora do país através de sua fluidez pelos centros políticos da Colônia. O autor cita a figura do crítico literário Otto Maria Carpeaux, para quem o

"coroamento do Barroco luso-brasileiro, não poderia ser visto no Brasil como arte bastarda ou espúria, muito menos decadente, pois é ela nossa verdadeira raiz nacional. Nunca tivemos arte clássica no sentido renascentista; daí a "prevalência" do Barroco, mesmo na arte atual brasileira - arquitetura, cinema, etc"

E continua, usando a citação de Afonso Avilla, que em seu O Lúdico e as Projeções do Mundo Barroco defende que

"No exemplo brasileiro, a redefinição crítica do barroco adquire significado próprio e acontece paralelamente a uma ânsia bem pronunciada, que anima os intérpretes mais lúcidos do fato nacional, de procurar localizar, sob um prisma de maior rigor, as matrizes e as linhas de tradição que determinam ou presidem o nosso desenvolvimento histórico e cultural. Entre as raízes remotas e os condicionamentos mais 
10 BEZERRA DE MENEZES, E. D. O Barroco como cosmovisão matricial do Êthos Cultural Brasileiro. Revista Ciências Sociais, 39-1. Universidade Federal do Ceará. 2008, p.65.

11 GONÇALVES, José Reginaldo. Autenticidade, Memória e Ideologias Nacionais: O problema dos patrimônios culturais. Revista Estudos Históricos, v.1 n.2. São Paulo: Fundação Getulio Vargas, 1988.p. 266-271.

12 GALLI, Claudio, et al. A teoria e prática do restauro arquitetônico: A influência da cultura europeia e seus desdobramentos na realidade brasileira. São Paulo: Revista Arq.urb, n. 16, Universidade São Judas Tadeu 2016, p. 12.

13 Eugène-Emmanuel Viollet-Le-Duc. Encyclopaedia Britannica. Disponível em: <https://www. britannica.com/biography/Eugene-Emmanuel-Viollet-le-Duc>. Acesso em 26/06/2020. decisivos, está por certo o barroco, não enquanto tão-só um estilo artístico, mas sim como fenômeno de maior complexidade - um estado de espírito, uma visão do mundo, um estilo de vida, de que as manifestações da arte serão a expressão sublimadora" 10 .

Essa abordagem sobre o Barroco permite que o espectador observe as igrejas de Minas Gerais através de uma suposta continuidade com o passado colonial, enxergando as características do Brasil nas formas arquitetônicas desses monumentos. A Nação passa a ser definida através dos mesmos adjetivos atribuídos ao patrimônio (como Barroco, Negro, Católico etc), e o sujeito nacional passa a ser entendido como um "autentico" portador de tais atributos. Mas, para esse discurso ser eficaz, a autenticidade histórica das construções não pode ser problematizada, pois a crença na materialidade da Nação é retoricamente possibilitada pela crença na autenticidade de seu patrimônio. ${ }^{11}$

Sobre a proteção desses patrimônios históricos, o que norteou a política do SPHAN entre sua fundação na década de 1930 e os anos 1970 foi uma restrição às obras arquitetônicas e de Arte erudita associadas ao passado nacional. Esse cenário só foi modificado com a criação do Pro-Memória, que passou a conservar também a Arte Popular, manifestações religiosas, antigas tecnologias, documentos etc. É interessante notar que, mesmo com a mudança de circunstâncias, Ouro Preto não deixou de ser valorizada.

As primeiras restaurações do patrimônio nacional seguiram a lógica da repristinação, desenvolvida sobretudo por Viollet-Le-Duc e que consiste em devolver os edifícios à sua forma original, apoiando-se "em documentos, evidências e estudos analíticos, mediante a remoção das partes adicionadas e a reintegração das lacunas". Os efeitos desse tipo de restauro podem ser observados nas obras realizadas no Liceu de Artes e Ofícios de Ouro Preto, cujas características mudaram drasticamente após a intervenção. Apesar das críticas ao método, acusado de negligenciar a ação do tempo sobre as construções, o que os Modernistas buscavam era uma forma ideal, o "valor simbólico do monumento assim como foi pensado em sua concepção". ${ }^{12}$

Essa busca guarda muita semelhança com as ideias do já citado Eugène-Emmanuel Viollet-le-Duc (1814-1879), que atuou como arquiteto, teórico e restaurador na França. Pupilo de Achille Leclère e inspirado pelo arquiteto Henri Labrouste, Viollet-le-Duc foi treinado como arqueólogo medievalista na restauração de Saint-Germain-l'Auxerrois, em 1838, e posteriormente integrou a Comissão de Monumentos Históricos, onde tornou-se uma figura de destaque. Dentre seus mais importantes trabalhos, encontramse os restauros da Catedral de Notre Dame, em 1844 e da Abadia de Saint-Denis, em 1846; além do seu papel no Service des Édifices Diocésains, onde supervisionou a restauração de diversos edifícios medievais. ${ }^{13}$

Para defender sua postura, Viollet-le-Duc buscava argumentos nas restaurações da Antiguidade, fosse ela Helenística, Asiática ou Egípcia. Ao tratar da Idade Média, por exemplo, ele apontava que pouquíssimos edifícios foram construídos de uma só vez, e que dificilmente algum deles não teria passado por transformações. Daí residiria a necessidade de apontar a idade e características de cada parte da obra antes de se iniciar uma restauração. Em suas palavras, 
14 VIOLLET-LE-DUC, Eugene. On Restoration. Londres: Sampson Low, Marston \& Co. 1875, p.36.

${ }^{15}$ CHOAY, Françoise. Alegoria do Patrimônio. São Paulo: Editora da Unesp, 2006. p. 185.

16 VIOLLET-LE-DUC, Op. Cit., p. 63.

17 Idem, p. 9.

18Idem, p. 35

${ }^{19} \mathrm{CHOAY}$, Françoise, Loc. Cit.

20 GALLI, Claudio, et al. A teoria e prática do restauro arquitetônico: A influência da cultura europeia e seus desdobramentos na realidade brasileira. São Paulo: Revista Arq.urb, n. 16, Universidade São Judas Tadeu 2016, p. 8.

21 GONÇALVES, José Reginaldo. Autenticidade, Memória e Ideologias Nacionais: O problema dos patrimônios culturais. Revista Estudos Históricos, v.1 n.2. São Paulo: Fundação Getulio Vargas, 1988, p. 268. é essencial, antes de qualquer trabalho de reparo, definir com certeza a idade de cada parte, formando uma espécie de descrição baseada em fontes fidedignas, sejam elas representações escritas ou gráficas. ${ }^{14}$ (Tradução nossa)

Com o que foi dito acima, podemos concluir que o restaurador deveria adquirir o maior número de informações sobre as condições existentes no momento em que o edifício foi criado, bem como suas necessidades e adaptações. Portanto, apesar do elevado grau do seu intervencionismo, que alterava significativamente os edifícios, não se pode negar o interesse que Viollet-le-Duc nutria pela História das técnicas e canteiros de obras. ${ }^{15}$ Em suas palavras, "o melhor plano é se colocar na posição do arquiteto original, e imaginar o que ele faria se voltasse ao mundo e tivesse o encargo que precisamos lidar à sua frente" (Tradução nossa). ${ }^{16}$

Para ele, "restaurar um edifício não é preservá-lo, repará-lo ou reconstruí-lo; é restituí-lo a um estado completo que pode nunca ter existido num momento dado" (Tradução nossa). ${ }^{17}$ Ao se deparar com restauros ou adições posteriores, por exemplo, o responsável pela intervenção deveria questionar se foi para fins funcionais ou estéticos. No primeiro dos casos, as mudanças deveriam ser mantidas, enquanto no segundo o edifício deveria ser restaurado à sua forma original, com o material retirado sendo substituídos por versões mais fortes e bem-colocadas. ${ }^{18}$

A segunda metade da sua carreira foi marcada pela busca de uma arquitetura verdadeiramente contemporânea, acusando os profissionais de sua época de serem meras cópias dos tempos anteriores. Para ele, através de uma análise racional da arquitetura do passado, seria possível descobrir os princípios que continuavam verdadeiros ao longo dos séculos", ajudando na elaboração de um novo sistema com características nossas. $^{19}$

Portanto, podemos perceber que apesar das diferenças entre o desenvolvimento do restauro e conservação de patrimônio na Europa e Brasil, há pontos em comum entre ambos os cenários, já que se trata de um tema compartilhado pelas sociedades em sua fase de formação identitária. Na Europa, esse processo se deu com maior fervor no Século XIX, com estudos relativos à Idade Média manifestados tanto nos "restauros em Estilo" dos castelos e igrejas, com Viollet-Le-Duc, quanto no processo de "medievalização" de cidades como Bolonha, na Itália. ${ }^{20}$ Já no Brasil, isso ocorreu na primeira metade do Século XX, sobretudo na região de Minas Gerais, com as heranças do Barroco.

Após o auge da cidade no período da mineração, Ouro Preto tornou-se uma das tantas localidades perdidas no interior do Brasil, principalmente após a perda do status de capital para Belo Horizonte, em fins do Século XIX. Já entre os anos 1920 e 30, a redescoberta da região pelos Modernistas iniciou a construção do culto à cidade, elevando-a à categoria de Monumento Nacional em 1933. Entre 1938 e 1942, diversas obras arquitetônicas foram tombadas pelo recém-criado SPHAN, contribuindo para a consolidação da área como um poderoso símbolo da identidade brasileira. ${ }^{21}$

Para construir o corpus patrimonial de regiões como Ouro Preto, o SPHAN se utilizou de referenciais estrangeiros sobre o tema, adequando-os às condições locais. Segundo a tese de doutorado de Claudia dos Reis e Cunha, que abordou as teorias e práticas 
22 CUNHA, Claudia dos Reis. Restauração: diálogos entre teoria e prática no Brasil nas experiências do IPHAN. Tese de Doutorado FAU-USP. São Paulo, 2010, p.64.

23 Idem, p. 65
24 ANDRADE, Rodrigo. Apud., CUNHA, Claudia dos Reis. Restauração: diálogos entre teoria e prática no Brasil nas experiências do IPHAN. Tese de Doutorado FAU-USP. São Paulo, 2010, p. 73.

${ }^{25}$ CUNHA, Claudia dos Reis. Op. Cit., p. 75.

26 COSTA, Lucio. Apud. CUNHA, Claudia dos Reis. Op. Cit., p. 78.

27 CUNHA, Claudia dos Reis. Op. Cit., p.78.

28 Idem, p. 79 presentes na atuação do órgão, os preservacionistas agiam em consonância com o espírito antropófago Modernista, devorando "referenciais exógenos para em seguida degluti-los e transformá-los em autêntica cultura nacional. ${ }^{22}$ Mesmo no caso de projetos como o redigido por Jair Lins, que serviria de base para o decreto que instituiu o SPHAN, temos referências às legislações preservacionistas de países Europeus, demonstrando que as práticas do Velho Continente já eram familiares aos profissionais deste lado do Atlântico. ${ }^{23}$

Além das leis europeias, sobretudo a francesa e italiana, Cunha aponta que as lideranças do SPHAN conheciam as discussões de teóricos como Camillo Boito e Gustavo Giovannoni (ainda que parcialmente ou de forma distorcida). Outra referência foi a Carta de Atenas, como podemos notar na fala de Rodrigo Melo Franco de Andrade, primeiro diretor da instituição:

Recentemente se reuniu em Atenas uma conferência internacional para assentar, na órbita mundial, as mesmas e oportunas medidas que o nosso Serviço objetiva e sob o alto e inspirado sentido de que os patrimônios históricos e artísticos nacionais transcendem e são de interesse da comunidade universal. ${ }^{24}$

A partir de tais referenciais, é possível questionar como os pressupostos teóricos até agora discutidos foram reinterpretados para realidade nacional, além da sua influência nas práticas de inventário, tombamento e restauração empreendidas pelo Serviço do Patrimônio Histórico e Artístico Nacional. As publicações de Lucio Costa e as correspondências entre Mário e Rodrigo de Andrade tornam-se ferramentas uteis para elucidar essa questão, pois apresentam algumas das características da Fase Heroica do órgão, enquanto Rodrigo esteve à sua frente. ${ }^{25}$

O dilema de reconstruir ou apenas conservar ruínas foi abordado por Lúcio Costa em sua primeira missão como Diretor da Divisão de Estudos e Tombamentos do SPHAN, quando inspecionou os remanescentes das Reduções Jesuíticas no Sul do país. Apesar de a recomendação da Carta de Atenas ser a recomposição dos monumentos com os vestígios encontrados, o arquiteto decidiu que "não se pode pensar em reconstruir São Miguel ou mesmo recompor qualquer de suas partes; os trabalhos deverão limitar-se, tão somente, a consolidar e conservar" ${ }^{26}$. Em contrapartida, ao tratar da construção de um Museu que abrigaria os restos das outras Reduções, Costa propôs que a estrutura fosse feita "aproveitando-se o material das próprias ruinas", enquanto a cobertura deveria ser feita com "telha antiga ou fabricada de acordo, não devendo empregar as modernas telhas de canal, cujo tamanho e aspecto destoariam do resto". 27

Em muitos casos, tanto Lucio Costa quanto os chefes regionais do órgão recomendavam a retirada de acréscimos posteriores das construções, em busca de uma originalidade histórica. Um exemplo disso é o Edifício da Alfândega, em Salvador, onde Costa sugeriu "aproveitar a oportunidade [das obras] e recuar a referida caixilharia para a prumada das colunas internas, reestabelecendo-se assim o aspecto original". Apesar de contrária às disposições em voga no campo da restauração, a supressão de adições posteriores era uma prática comum entre os técnicos do Patrimônio, em sua busca por uma unidade e coerência estilística dos monumentos. ${ }^{28}$

Enquanto certos lugares, datas e eventos eram privilegiados pelo tombamento, outros eram obscurecidos através da exclusão da lista de bens protegidos, e os critérios nos 
${ }^{29}$ CUNHA, Claudia dos Reis. Restauração: diálogos entre teoria e prática no Brasil nas experiências do IPHAN. Tese de Doutorado FAU-USP. São Paulo, 2010. p. 82.

30 RUBINO, Silvana, Apud. CUNHA, Claudia dos Reis. Op. Cit., p. 87.

31 CUNHA, Claudia dos Reis. Op. Cit., p. 82

32 Idem, p.89.

33 GALLI, Claudio, et al. A teoria e prática do restauro arquitetônico: A influência da cultura europeia e seus desdobramentos na realidade brasileira. São Paulo: Revista Arq.urb, n. 16, Universidade São Judas Tadeu 2016, p. 12.

${ }^{34}$ CUNHA, Claudia dos Reis. Restauração: diálogos entre teoria e prática no Brasil nas experiências do IPHAN. Tese de Doutorado FAU-USP. São Paulo, 2010, p.89. ajudam a enxergar qual passado a Instituição queria deixar como herança às gerações futuras. Durante a Fase Heroica, foi buscada uma pureza estilística medida pela similaridade dos monumentos com modelos previamente determinados, de forma que eram valorizados à medida que se aproximavam do "tipo" idealizado pelas teses sobre o desenvolvimento da arquitetura brasileira. ${ }^{29} \mathrm{~A}$ memória nacional só tinha espaço para o que era visto como herança positiva pelos Modernistas, levando Silvana Rubino a apontar que

Nesse processo seletivo, o SPHAN construiu um "mesmo" em oposição a um "outro". [...] O SPHAN elegeu um Brasil antepassado que exclui alguns atores contemporâneos ao delimitar claramente de quem "descendemos". Não é um discurso da superioridade branca, lusitana e cristã conferido pela detração do outro e sim pela sua exclusão, por meio da construção de um elo de ligação com o passado que remete a bisavós, antepassados e ancestrais dignificados. O melhor do passado do SPHAN não traz à luz contrastes. Ao contrário, estabelece uma continuidade. ${ }^{30}$

Critérios similares aos adotados para monumentos isolados também foram aplicados à preservação de sítios urbanos, criando o que os habitantes de tais núcleos passaram a chamar de "Estilo Patrimônio". Ou seja, a manutenção das características "originais" através da adequação de edificações corrompidas por transformações posteriores, mas também pela construção de novos edifícios em harmonia com o entorno. ${ }^{31}$ Esse tipo de abordagem marcou a atuação do órgão em Ouro Preto, ficando nítida no parecer de Lúcio Costa sobre o conjunto arquitetônico e urbanístico da cidade, em 1958.

Para as "obras de maior vulto, relacionadas com a restauração da cidade propriamente dita", ele sugeriu que "o tombamento obriga a providencias de caráter radical quando se trata de preservar ou repor a coisa no seu estado original". Isso implicou na demolição e recomposição de diversas fachadas e prédios, resultando em uma falsificação do conjunto edificado da cidade em prol da ambiência harmônica. ${ }^{32}$ Para criar um espaço sem dissonâncias, as manifestações dinâmicas que constituem a Urbe foram censuradas, ocultando assim sua veracidade histórica. ${ }^{33}$

A partir disso, Claudia dos Reis e Cunha conclui que as tomadas de decisões dos patrimonialistas nas primeiras décadas de atuação do órgão eram variadas. Podemos perceber que, apesar de em alguns momentos estarem em consonância com as teorias contemporâneas, muitas vezes retomavam práticas "descartadas", como as restaurações estilísticas defendidas por Viollet-Le-Duc ao longo do Século XIX. Segundo a autora, esse quadro manteve-se praticamente inalterado até a aposentadoria de Rodrigo de Andrade, em 1967, quando foi substituído por Renato Soeiro. ${ }^{34}$

Por fim, essa discussão nos permite apontar como algumas das ideias de Viollet-Le-Duc inspiraram o restauro de bens ligados ao passado colonial brasileiro. No campo teórico, diversas semelhanças são encontradas entre suas preposições e as falas de Mário de Andrade, o principal responsável pelo discurso Modernista de uma identidade nacional que se manifesta através do Barroco. Já na prática, o restauro da cidade histórica de Ouro Preto, supervisionado por Lúcio Costa, se deu através da repristinação defendida pelo arquiteto francês.

Enquanto o discurso de Viollet-Le-Duc floresceu em meio à busca pela consolidação das identidades nacionais na Europa, a restauração de Ouro Preto liga-se diretamente 
à idealização do Barroco como origem da cultura nacional. Se nos casos da França, Itália e Alemanha a solidificação dessa identidade encontrava-se na Idade Média ou Antiguidade Clássica, o Brasil Modernista elegeu o Período Colonial como o representante de sua Gênese.

\section{Referências bibliográficas}

BEZERRA DE MENEZES, E. D. O Barroco como cosmovisão matricial do Êthos Cultural Brasileiro. Revista Ciências Sociais, 39-1, Universidade Federal do Ceará. 2008, p. 52-65.

BRUSADIN, Leandro; DA SILVA, Rafael Henrique. O USO TURÍSTICO DO PATRIMÔNIO CULTURAL EM OURO PRETO. Ilhéus: Revista Cultur, ano 06, n.1. UESC. 2012, p.77-82.

CHAUI, Marilena. "Brasil: mito fundador e sociedade autoritária". In: ROCHA, André (org.). Marilena Chauí. Manifestações ideológicas do autoritarismo brasileiro. Belo Horizonte/ São Paulo; Autêntica/ Fundação Perseu Abramo, 2013, vol. 2, p. 147-237.

CHOAY, Françoise. Alegoria do Patrimônio. São Paulo: Editora da Unesp, 2006, p. 149-167.

CUNHA, Claudia dos Reis. Restauração: diálogos entre teoria e prática no Brasil nas experiências do IPHAN. Tese de Doutorado FAU-USP. São Paulo, 2010.

GALLI, Claudio, et al. A teoria e prática do restauro arquitetônico: A influência da cultura européia e seus desdobramentos na realidade brasileira. São Paulo: Revista Arq.urb, n. 16, Universidade São Judas Tadeu 2016, p.9-12.

GONÇALVES, José Reginaldo. Autenticidade, Memória e Ideologias Nacionais: O problema dos patrimônios culturais. Revista Estudos Históricos, v. 1 n.2. São Paulo: Fundação Getulio Vargas, 1988, p. 266-271.

HOBSBAWM, Eric. A invenção das tradições. Rio de Janeiro; Paz e Terra, 2006, p. 9-23.

NATAL, Caion Meneguello. Ouro Preto: A construção de uma cidade histórica, 1891-1933. Dissertação de Mestrado. Campinas: UNICAMP, 2007, p. 109-119.

Verbete sobre Eugène-Emmanuel Viollet-Le-Duc. EncyclopaediaBritannica. Disponível em: $<$ https://www.britannica.com/biography/Eugene-Emmanuel-Viollet-le-Duc>. Acesso em 10/06/2019.

VIOLLET-LE-DUC, Eugene. On Restoration. Londres: Sampson Low, Marston \& Co. 1875, p. 9-63. 